\title{
International R\&D Spillovers and Convergence Among OECD Countries
}

\author{
Mark F. Funk* \\ Saint Louis University
}

\begin{abstract}
This paper examines the effect of relative productivity levels on international knowledge flows. Using the Coe and Helpman (1995) data on research, I show how separating the sample into distinct groups allows the relationship between relative productivity and research spillovers to be estimated. Since the data are nonstationary, the panel cointegration techniques recently developed by Kao and Chiang (1999) are used. I find that the observed flow of knowledge is consistent with a simple model of catch-up to the technological frontier. Countries benefit more from the research of more-advanced nations than from the research of nations with similar productivity levels.
\end{abstract}

- JEL Classifications: Convergence, Research Spillovers

- Key Words: O3

\section{Introduction}

This paper asks whether the observed patterns of knowledge flows between OECD nations are consistent with convergence. While attempts to uncover the patterns of international knowledge flows have become common (e.g., Coe and Helpman (1995), Eaton and Kortum (1996)), the emphasis has been on determining the relationship between knowledge flows and trade flows. The relationship between knowledge flows and relative productivity levels has been of

\footnotetext{
*Corresponding Address: Mark F. Funk Assistant Professor, Department of Economics Saint Louis University 3674, Lindell Boulevard St. Louis MO 63103 USA. Tel: +1-314-977-3844, Email: funkmf@slu.edu (2)000-Center for International Economics, Sejong Institution, all Rights Reserved.
} 
secondary concern. This neglect is odd given the prominence of the convergence literature. Convergence through knowledge transfers implies that less-advanced countries receive flows of knowledge from more technologically advanced nations. Knowledge, in this case, flows in one direction-from frontier nations to less-advanced nations and as a nation approaches the technological frontier the benefits from such flows diminish. This paper uses OECD data on research and productivity to test whether the observed pattern of knowledge flows is consistent with this model of catch-up to the frontier.

The possible effects of relative productivity on knowledge flows are more complex than suggested by this simple version of the convergence hypothesis. The knowledge flows that influence long-run growth occur between innovators. For these knowledge flows to have dynamic effects, the knowledge importer must be capable of converting foreign knowledge into new innovations. Any relationship between productivity and foreign knowledge then depends upon the knowledge importer's ability to adapt foreign knowledge to their own unique circumstances. The adapting of foreign knowledge is a complicated affair. As Abramovitz (1986) points out, in order for a country to adopt foreign technology it must have factor supplies, production processes, and industrial production structure reasonably similar to those of the nation where the technology was created. This criterion of "technological congruence," in Abramovitzs words, is related to the notion of economic "closeness" used in the studies of intranational knowledge spillovers, e.g., Jaffe (1986) and Griliches (1991).

Technological congruence implies that research flows from nations with similar technology levels are potentially more potent than research flows from dissimilar nations. If knowledge from more-advanced but relatively distant countries is less useful than the knowledge from countries closer in a technological sense, then the potential exists for convergence among sub-groups of countries, without any overall convergence. This paper also tests whether the observed pattern of knowledge flows is consistent with sub-group convergence.

This study examines how relative productivity levels influence international knowledge flows. It does not test whether convergence occurs. Some factor other than knowledge flows may motivate convergence, such as shifts in sectoral output shares. Even if knowledge flow patterns are consistent with convergence, other factors may counteract the flows. For example, if trade leads to specialization, then even in the presence of knowledge flows there need not be a convergence in productivity. 
The rest of this paper proceeds as follows. Section II presents a simple model of international knowledge spillovers. Section III discusses the data and panel cointegration methodology. Section IV provides the empirical results. The results strongly indicate that knowledge flows among OECD nations are consistent with a simple model of catch-up to the frontier. Section V sets the results in context and provides concluding remarks.

\section{Model}

The following model captures the important features of the knowledge-based growth theories and facilitates the empirical discussion. Aspects of this simple model can be found in several sources, but the model owes its present form to Keller (1997). More complete models of knowledge diffusion, research, and productivity can be found in Grossman and Helpman (1991) and Aghion and Howitt (1998). Assume output $Q$ is a function of capital $K$ and a composite commodity $D$, where $D$ is an index of horizontally differentiated goods. Then in country $i$ at time $t$, output may be defined as

$$
Q_{i t}=X_{i t} K_{i t}^{\alpha} D_{i t}^{I-\alpha}
$$

where $0<\alpha<1$, and

$$
X_{i t}=e^{\Sigma \delta_{i t} x_{i}},
$$

where $x_{i}$ is a dummy variable that allows differences in production for reasons that are not included in the model.

The assumption that the inputs comprising $D$ are imperfect substitutes with an elasticity of substitution greater than one allows the producers to exhibit the familiar "variety-loving" behavior. The inventor of any one of the inputs is assumed to have monopoly power on any product-specific knowledge. The potential returns from the privately held knowledge motivate research. However, some of the general knowledge created during the innovation process may be nonrivalrous and at least partially non-excludable. Define the index $D$ as

$$
D_{i t}=\left[{ }_{0}^{n_{i}}\left[z_{i}(s)^{1-\alpha} d s\right]^{1 / 1-\alpha}\right.
$$

where $n_{i t}$ is the number of available inputs in country $i$ at time $t$, and $z_{i}$ is the quantity produced of each input. With this specification, output in the final goods 
sector increases with the number of available input varieties. Since the inputs are imperfect substitutes, in a symmetric equilibrium the price $p$ and quantity $\hat{z}$ of each good is the same for all goods. $D$ may then be defined as

$$
D_{i t}=n_{i t}^{1 / 1-\alpha} \hat{z}_{i t}
$$

Suppose the blueprints for new inputs are created solely through R\&D, thereby ruling out feedback from the final goods sector. Define the time $t$ creation rate of new inputs as a function of current $\mathrm{R} \& \mathrm{D}$ expenditures $R_{t}$. Then the stock of inputs at time $t=T$ is

$$
n_{i}(t)=\int_{-\infty}^{T} n_{i}(t) d t=\int_{-\infty}^{T} R D(t) d t=S_{i t}^{d}
$$

where $S^{d}$ is the domestic R\&D stock, defined as the simple sum of previous R\&D.

Assuming it takes one labor unit to produce one unit of input, the total amount of labor used will be the number of available inputs $n$ multiplied by the quantity of each input $z$, or $L=n z$. Substituting into Equation (4) yields

$$
D_{i t}=n^{\frac{\alpha}{1-\alpha}} L_{i t}
$$

Substituting Equation (6) into Equation (1) yields

$$
Q_{i t}=X_{i t} K_{i t}^{\alpha} L_{i t}^{1-\alpha} n_{i t}^{\alpha}
$$

If we define total factor productivity $\mathrm{F}$ as output divided by the weighted capital and labor inputs, we then have productivity increasing with the number of different inputs available:

$$
F_{i t}=X_{i t} n_{i t}^{\alpha}
$$

With international trade, final goods producers can also import inputs. Given the issues of technological congruence, foreign inputs may not have the same influence on productivity as domestic inputs. Allowing the elasticity of productivity to differ between domestic and foreign inputs yields

$$
F_{i t}=X_{i t} n_{i t}^{\alpha} n_{j t}^{\gamma}
$$

where $n_{j}$ are the imported inputs. Substituting in Equation (5) and taking logs yields the equation used by Coe and Helpman (1995):

$$
\ln F_{i}=\text { á }+ \text { ád }^{d} \ln S_{i}^{d}+\text { ád }^{f} \ln S_{i}^{f}
$$


Equation (10) defines productivity in country $i$ as a function of the domestic research stock and the stock of research in foreign nations.

Coe and Helpman's specification has been criticized on a number of points. Engelbrecht (1998) adds GDP relative to the US as a catch-up variable, and finds the addition has no effect on the estimated research spillover. Keller (1998) questions the use of trade-based weights in the construction of foreign R\&D stocks, finding that randomly chosen weights provide similar results. Kao, Chiang, and Chen (1999) find that Coe and Helpman's results are not robust to panel cointegration techniques.

This paper accounts for each of these critiques in considering the effects of relative productivity on knowledge flows. Few studies directly consider the relationship between knowledge flows, relative productivity levels, and convergence. Evenson (1997) finds that foreign R\&D has a negligible effect on TFP growth in his sample of 11 OECD nations, which implies that convergence is not motivated by international knowledge flows. Eaton and Kortum (1996) explain the pattern of international knowledge diffusion by using bilateral patent applications as a measure of international knowledge flows. They find a highly unstable relationship between patenting and relative productivity levels that is statistically significant only when an explicit measure of the source country's innovation effort is excluded.

The convergence literature also offers little evidence on whether knowledge flow patterns are consistent with convergence. The information that does exist is indirect. Bernard and Jones (1996a, 1996b) suggest the apparent convergence in OECD aggregate productivity does not extend to the sectoral level. The absence of convergence at the sectoral level, particularly in manufacturing, implies that the pattern of knowledge flows between OECD countries may be inconsistent with convergence. Whether the pattern of knowledge flows would motivate convergence remains an open question.

Determining the relationship between knowledge flows and relative productivity levels is complicated by several considerations. For one, using the ratio of the productivity levels as a regressor (either alone or interacted with another variable) implies identical knowledge flows between equally distant nation-pairs, regardless of the nation-pair's technology levels relative to the rest of the world. One would not, however, necessarily expect knowledge flows between two relatively advanced nations to be the same as the knowledge flows between two less-advanced, but equally distant, nations. A more robust approach would allow 
the knowledge flows between any two nations to differ with their distance from the frontier. Secondly, in the knowledge flow literature the foreign knowledge stock is weighted to reflect the technological, economic, or geographic distance between the source and the recipient. Unfortunately, weighting foreign research by relative productivity or interacting foreign research with a measure of relative productivity

Table 1. Summary Statistics

\begin{tabular}{|c|c|c|c|c|}
\hline & \multicolumn{4}{|c|}{ Foreign R\&D Stocks } \\
\hline & $\begin{array}{c}\text { Coe and Helpman } \\
\text { TFP indices } \\
\text { TFP }_{1990} / \mathrm{TFP}_{1971} \\
\end{array}$ & $\begin{array}{l}\text { SIMILAR }_{1990} \\
\text { SIMILAR }_{1971}\end{array}$ & $\begin{array}{l}\text { OTHER }_{1990} / \\
\text { OTHER }_{1971}\end{array}$ & $\begin{array}{c}\text { Hall and Jones } \\
1988 \text { TFP } \\
\text { USA }=1.000 \\
\end{array}$ \\
\hline USA & 1.076 & 1.767 & 6.028 & 1.000 \\
\hline France & 1.373 & 1.838 & 2.509 & 1.126 \\
\hline Italy & 1.405 & 1.375 & 2.404 & 1.207 \\
\hline UK & 1.282 & 1.868 & 8.600 & 1.011 \\
\hline Canada & 1.134 & 2.005 & 6.379 & 1.034 \\
\hline \multirow{2}{*}{$\begin{array}{l}\text { Spain } \\
\text { TIER } 1 \text { Average }\end{array}$} & 1.180 & 1.061 & 3.105 & 1.107 \\
\hline & 1.242 & 1.652 & 4.837 & \\
\hline Germany & 1.212 & 1.509 & 1.829 & 0.912 \\
\hline Australia & 1.116 & 1.794 & 2.287 & 0.856 \\
\hline Austria & 1.207 & 2.059 & 3.320 & 0.979 \\
\hline Belgium & 1.352 & 1.565 & 3.769 & 0.978 \\
\hline Israel & 1.328 & 2.108 & 1.946 & 0.817 \\
\hline Netherlands & 1.233 & 1.832 & 3.165 & 0.946 \\
\hline Sweden & 1.119 & 2.049 & 2.377 & 0.897 \\
\hline \multirow{2}{*}{$\begin{array}{l}\text { Switzerland } \\
\text { TIER } 2 \text { Average }\end{array}$} & 1.088 & 1.823 & 1.893 & 0.883 \\
\hline & 1.207 & 1.906 & 2.745 & \\
\hline Japan & 1.664 & 3.492 & 1.774 & 0.658 \\
\hline Denmark & 1.195 & 11.128 & 1.626 & 0.705 \\
\hline Finland & 1.445 & 8.679 & 1.941 & 0.728 \\
\hline Greece & 1.197 & 2.012 & 1.693 & 0.674 \\
\hline Ireland & 1.345 & 18.537 & 1.676 & 0.709 \\
\hline New Zealand & 0.950 & 8.128 & 1.691 & 0.631 \\
\hline Norway & 1.514 & 3.795 & 2.067 & 0.699 \\
\hline \multirow{2}{*}{$\begin{array}{l}\text { Portugal } \\
\text { TIER } 3 \text { Average }\end{array}$} & 1.286 & 2.700 & 1.113 & 0.755 \\
\hline & 1.325 & 7.308 & 1.697 & \\
\hline \multicolumn{5}{|c|}{ IPS Panel Unit-Root Test: (5\% sign.=-1.65) } \\
\hline \multirow{2}{*}{ T-bar } & TFP & SIMILAR & OTHER & \\
\hline & 0.75 & -1.41 & 0.53 & \\
\hline
\end{tabular}


causes a correlation by construction with the dependent productivity variable.

This paper avoids these pitfalls by breaking the sample into sub-groups and allowing knowledge flows between countries to vary both with the bilateral technological distance and with the distance from the technological frontier. Separate foreign R\&D stocks are constructed for each country based on the relative productivity of the foreign country. The relative productivity measure is based on the Hall and Jones (1999) estimates of TFP. ${ }^{1}$ For each nation, the remaining nations were divided into two groups. The first group, denoted SIMILAR, includes all foreign nations whose TFP levels are within one standard deviation of the domestic TFP level. The second group, OTHER, includes the foreign nations whose productivity levels are more than one standard deviation different from the domestic productivity level. Two foreign R\&D stocks were then created for each country. The first consists of the research conducted by the countries in the group SIMILAR. The second consists of the research conducted by the countries in the group OTHER. This approach highlights the role relative productivity plays in knowledge flows. If knowledge flows primarily between similar countries, then we should see knowledge flows emerging primarily from the R\&D of similar nations.

The "standard deviation" criterion for determining the grouping of foreign research is somewhat arbitrary. Robustness tests explore other criteria along with other measures of relative productivity. However, this criterion has the nice feature of dividing the sample into three distinct groups. The high productivity nations, labeled Tier 1 in Table 1, are all within one standard deviation of the most productive nation but more than one standard deviation from the least productive nation. The low productivity nations, labeled Tier 3 in Table 1, are all within one standard deviation of the lowest productivity nation but more than one standard deviation from the most productive nation. Nations that are more than one standard deviation from both the highest productivity nation and the lowest productivity nation comprise the middle group, labeled Tier 2 .

By dividing the sample into natural tiers, this approach captures the effects that

${ }^{1}$ Hall and Jones (1999) measure productivity for the year 1988 as the Solow residual using data on output per worker, labor input, average educational attainment, and physical capital. National income, product account, and labor force data come from the Penn World Tables Mark 5.6. Average educational attainment comes from Barro and Lee (1993). Physical capital stocks are constructed using the perpetual inventory method. Other details of the data construction can be found in Hall and Jones (1999). 
both the distance from the frontier and the distance between countries have on knowledge flows between countries. Although the research of similar nations may be more useful than the research of dissimilar nations, the nation's distance from the frontier may also affect the impact of any knowledge flows it receives. In other words, the less-advanced countries of Tier 3 may not benefit as much from the research of similar nations as the countries of Tier 1. Likewise, the benefits from dissimilar nations may differ across countries. The nations at the technological frontier are unlikely to find compatible research performed by nations some distance from the frontier. Tier 3 nations, however, may be able to adopt technologies developed by distant but more-advanced nations. To address this possibility, dummy variables relating to each tier divide the sample into three distinct groups, with each group having a unique estimate of the impact of foreign research from SIMILAR countries and OTHER countries. ${ }^{2}$

With these considerations, Equation 1.10 above becomes

$$
\begin{aligned}
\ln F_{i}= & \alpha_{i}+\alpha^{d} \ln S^{d}+\alpha^{G 7} G 7 \ln S^{d}+\alpha^{s} \ln S^{s}+\alpha^{s} \ln S^{s}+\alpha^{o} \ln S^{o}+ \\
& a^{s 2} T 2 \ln S^{s}+a^{o 2} T 2 \ln S^{o}+a^{s 3} T 3 \ln S^{s}+a^{s 3} T 3 \ln S^{o}
\end{aligned}
$$

where $F$ is TFP indices, $S^{d}$ is the domestic R\&D stock, $S^{s}$ is the foreign R\&D stock from SIMILAR countries, $S^{\circ}$ is the foreign R\&D stock from OTHER countries, and $T 2$ and $T 3$ are dummy variables for the Tier 2 and Tier 3 countries respectively. ${ }^{3}$ Since the benefits of domestic research may depend on the domestic market size, as Coe and Helpman (1995) find, the domestic research stock $S^{d}$ is interacted with a dummy for the $G 7$ nations $(G 7){ }^{4}$

\section{Data and Empirical Methods}

\footnotetext{
${ }^{2}$ If knowledge flows from technological leaders to followers, the Tier 2 estimate of OTHER may be biased downward since $O T H E R$ includes research from both more-advanced and lessadvanced nations. To avoid this, the Tier 2 OTHER R\&D stock includes only the research of more-advanced nations. The OTHER research stock of Tier 2 and Tier 3 now includes only $\mathrm{R} \& \mathrm{D}$ from more-advanced nations. The Tier 1 OTHER research stock contains only the research of less- advanced nations.

${ }^{3}$ In the estimation, all variables are indexed with 1985 as the base year. The Lichtenberg and van Pottelsberghe de la Potterie (1998) criticism of Coe and Helpman's (1995) use of indices is not relevant here since the foreign $R \& D$ stocks are interacted only with a constant, rather than a changing import share.

${ }^{4}$ A referee suggested interacting domestic research with a Tier 1 dummy instead of the G7 dummy (the Tier 1 dummy with Japan and Germany and without Spain is the same as the G7 dummy). The resulting coefficient proved small (less that .01) and insignificant, suggesting that when it comes to domestic research, domestic market size is more important than relative productivity levels. A G7 dummy interacted with the foreign R\&D stocks also proved insignificant.
} 
The business-sector TFP indices and the annual data on domestic research stocks are from Coe and Helpman (1995); see their appendix for data construction details. The domestic research stocks were then used to construct foreign research stocks as described above. Consistent with the findings of Ben-David (1997) and Kao, Chiang, and Chen (1999), bilateral export shares are used to weight both foreign R\&D stocks to reflect access to foreign knowledge. ${ }^{5}$ The trade data are taken from the IMF's Direction of Trade annual.

Table 1 shows the 1990:1971 ratio for Coe and Helpman's TFP measure and both foreign R\&D stocks, and provides the Hall and Jones 1988 TFP levels indexed to the USA. There are now several tests for nonstationarity in panel data. The power of panel unit-root tests is substantially greater than individual time-series tests. Im, Pesaran, and Shin (1997) suggest using the average ADF t-statistic, which they call the t-bar. They show that for small samples the power of the t-bar test substantially exceeds Levin and Lin's (1993) test. T-bar tests indicate the data are nonstationary. Nonstationary data increases the risk of spurious results: As Kao and Chiang (1999) demonstrate, standard regression techniques such as ordinary least squares may indicate a relationship where none in fact exists.

Recent advances in panel cointegration now allow reliable estimates of the longrun relationship to be obtained. This paper uses the fully modified (FMOLS) and dynamic OLS (DOLS) methods discussed by Kao and Chiang (1999) to estimate the cointegrating vector and inference statistics. OLS estimates are also provided in order to better assess the sensitivity of the parameter estimates. To briefly describe these procedures, consider the fixed-effect panel regression $Y_{i t}=\alpha_{i}+X_{i t} \beta+v_{i t}$

With nonstationary variables, an OLS regression suffers from serial correlation. Moreover, since the cointegration literature does not assume exogenous regressors, estimation must account for potential endogenous feedback between $X$ and $Y^{6}$ The panel DOLS estimator builds on the time-series approach of Saikonnen (1991). The addition of lags of the differenced I(1) regressors corrects for serial correlation, while including leads of the differenced regressors corrects for the potential endogeneity. The DOLS regression is:

\footnotetext{
${ }^{5} \mathrm{By}$ adjusting the contribution of foreign $\mathrm{R} \& \mathrm{D}$ to the foreign knowledge stock, the weights reflect preconceptions of the knowledge sources and recipients, the proportion of knowledge that is spillable, and the channels of knowledge diffusion. As such, the weights may reflect the geographic, technological, or economic distance between the research performer and the spillover recipient.

${ }^{6}$ Engelbrecht (1999) also notes a possible feedback between R\&D and productivity.
} 


$$
Y_{i t}=\alpha_{i}+X_{i t} \beta+\sum_{j=-q 1}^{q 2} c_{i j} \Delta X_{i t+j}+\mu_{i t}
$$

As a two-step procedure, the FMOLS estimator corrects for endogeneity and serial correlation by adjusting an initial OLS estimator. The FMOLS estimator treats the endogenous feedback effect nonparametrically in the second step, as in Phillips and Hansen (1990). The endogeneity correction collects the residuals from an OLS regression and uses them to modify the dependent variable. The FMOLS estimator can be shown as:

$$
\hat{\beta}_{F M}=\left[\sum_{i=1}^{N} \sum_{i=1}^{N}\left(X_{i t}-\bar{X}_{i}\right)\left(X_{i t}-\bar{X}_{i}\right)^{\prime}\right]^{\perp}\left[\sum_{i=1}^{N}\left(\sum_{t=1}^{I}\left(\hat{X}_{i t}-\hat{X}_{i}\right) \bar{Y}_{i t}^{+}-T \hat{\Delta}_{\varepsilon u}^{+}\right)\right]
$$

where $\Delta_{\varepsilon u}{ }^{+}$is the serial correlation correction term and $Y_{i t}^{+}$is the endogeneity correction. For further details, see Kao and Chiang (1999) and Pedroni (1996).

Kao and Chiang (1999) investigate the asymptotic and the finite sample properties of the OLS, FMOLS, and DOLS estimators. The advantage of these panel estimators over standard time-series regressions, they note, is that each estimator is super-consistent. Asymptotically, the OLS estimator is normal with a nonzero mean, while both the FMOLS and DOLS estimators are normal with zero means. In small samples, such as the OECD since 1970 used in this paper, they find that the OLS has a non-negligible bias. The FMOLS does not improve over the OLS in general, probably because of its dependence on an initial (possibly biased) OLS estimate. Kao and Chiang (1999) recommend the DOLS estimator, which has much smaller finite sample biases. For inference tests, the DOLS tstatistic is well approximated by a standard $\mathrm{N}(0,1)$. The FMOLS and OLS $\mathrm{t}-$ statistics do not perform as well, which suggests caution should be exercised when using these estimators in small samples.

McCoskey and Kao (1998) recommend a LM test of the null of panel cointegration. The LM test statistic is defined as:

$$
L M=\frac{\frac{1}{N} \sum_{i=1}^{N} \frac{1}{T^{2}} \sum_{i=1}^{T} S_{i t}^{2}}{\hat{w}^{2}}
$$

where $S_{i t}$ is the partial sum process of the estimated residuals of a regression with nonstationary variables. Large values of LM correspond to estimating 
nonstationary residuals and result in rejection of the null of cointegration. The LM test requires efficient estimation of the cointegrated relationship; only the DOLS and FMOLS techniques satisfy this requirement.

\section{Empirical Results}

The results in Table 2 clearly show the different effects of research flows from similar nations and dissimilar nations. Tier 1 nations receive sizable research flows only from similar Tier 1 nations. Tier 2 and Tier 3 nations receive very weak knowledge flows from comparable nations in Tier 2 and Tier 3. The DOLS estimated elasticity of productivity with respect to R\&D from similar nations for Tier 1 is about 0.12 (statistically significant), and for Tiers 2 and 3 the estimated elasticity is just 0.04 and 0.014 , respectively. However, nations in Tiers 2 and 3 benefit much more from the R\&D performed by dissimilar nations. The Tier 2 and Tier 3 estimated elasticity on the OTHER R\&D stocks are 0.08

Table 2. Knowledge Diffusion

\begin{tabular}{|c|c|c|c|}
\hline & OLS & FMOLS & DOLS \\
\hline$S^{d}$ & $.051(5.94) *$ & $.025(1.42)$ & $.035(1.66)$ \\
$G{ }^{d} S^{d}$ & $.125(7.53) *$ & $.113(3.09) *$ & $.080(1.83) * *$ \\
& & & \\
SIMILAR & $.145(5.72) *$ & $.122(2.88) *$ & $.123(2.44) *$ \\
TIER $2 *$ SIMILAR & $-.150(-4.79) *$ & $-.095(-1.78) * *$ & $-.083(-1.31)$ \\
TIER3*SIMILAR & $-.115(-4.32) *$ & $-.109(2.46) *$ & $-.109(-2.07) *$ \\
& & & \\
OTHER & $-.026(-1.51)$ & $-.009(-.303)$ & $.021(.062)$ \\
TIER $2 *$ OTHER & $.123(5.48) *$ & $.103(2.68) *$ & $.060(1.31)$ \\
TIER3*OTHER & $.154(5.77) *$ & $.188(4.20) *$ & $.168(3.16) *$ \\
& & & -4.88 \\
LM test & - & Fail to Reject & Fail to Reject \\
$\mathrm{H}_{\mathrm{o}}$ : cointegration & & & \\
\hline
\end{tabular}

Notes: Dependent variable=TFP (total factor productivity Coe and Helpman (1995) indices), Number of observations $=352$. All variables are indexed and are in log-levels, $S^{d}=$ domestic $R \& D$ stock; SIMILAR=foreign R\&D stock from similar nations; OTHER=foreign R\&D stock from dissimilar nations; $G 7=$ dummy for the $G 7$. Absolute t-statistics in parentheses. *=significant at the 5\% level. 1 lead and 2 lags of the first-differences of the nonstationary regressors were included in the DOLS regression. All equations include unreported group fixed effects, LM test values less than 1.645 indicate cointegration, The estimation was performed in GAUSS using the programs for FMOLS and DOLS provided by Kao on his internet homepage http://web.syr.edu/ cdkao/ 
to 0.09 . For Tier 1, knowledge flows from dissimilar nations are near zero and insignificant.

Table 3 shows the estimated impact of domestic and foreign $R \& D$ on

Table 3. Estimated Impact of Research on Productivity

\begin{tabular}{|cccccc|}
\hline & $\begin{array}{c}\text { Actual TFP } \\
\text { Growth }\end{array}$ & $\begin{array}{c}\text { Predicted } \\
\text { TFP Growth }\end{array}$ & $\begin{array}{c}\text { Growth due to } \\
\text { Domestic }\end{array}$ & $\begin{array}{c}\text { Growth due to Growth due to } \\
\text { SIMIL }\end{array}$ & OTHER \\
\hline USA & 0.076 & 0.147 & 0.060 & 0.062 & 0.025 \\
France & 0.239 & 0.172 & 0.056 & 0.101 & 0.015 \\
Italy & 0.239 & 0.185 & 0.100 & 0.072 & 0.013 \\
UK & 0.206 & 0.123 & 0.016 & 0.079 & 0.028 \\
Canada & 0.078 & 0.182 & 0.084 & 0.076 & 0.022 \\
Spain & 0.093 & 0.079 & 0.043 & 0.021 & 0.014 \\
\cline { 2 - 6 } & 0.155 & 0.148 & 0.060 & 0.068 & 0.020 \\
\cline { 2 - 6 } & & & & & \\
Germany & 0.137 & 0.157 & 0.093 & 0.032 & 0.031 \\
Australia & 0.108 & 0.100 & 0.053 & 0.020 & 0.028 \\
Austria & 0.095 & 0.119 & 0.029 & 0.037 & 0.053 \\
Belgium & 0.179 & 0.128 & 0.022 & 0.026 & 0.080 \\
Israel & 0.151 & 0.150 & 0.064 & 0.008 & 0.078 \\
Netherlands & 0.113 & 0.128 & 0.011 & 0.031 & 0.085 \\
Sweden & 0.079 & 0.125 & 0.033 & 0.047 & 0.045 \\
Switzerland & 0.046 & 0.057 & 0.008 & 0.029 & 0.021 \\
\cline { 2 - 6 } & 0.114 & 0.120 & 0.039 & 0.029 & 0.053 \\
\cline { 2 - 6 } & & & & & \\
Japan & 0.379 & 0.254 & 0.135 & 0.003 & 0.115 \\
Denmark & 0.135 & 0.149 & 0.026 & 0.029 & 0.094 \\
Finland & 0.283 & 0.181 & 0.039 & 0.017 & 0.124 \\
Greece & 0.155 & 0.201 & 0.065 & 0.015 & 0.121 \\
Ireland & 0.177 & 0.110 & 0.037 & 0.026 & 0.046 \\
New Zealand & -0.128 & 0.107 & 0.020 & 0.017 & 0.070 \\
Norway & 0.271 & 0.182 & 0.040 & 0.006 & 0.136 \\
Portugal & 0.138 & 0.056 & 0.022 & 0.014 & 0.020 \\
\hline & 0.176 & 0.155 & 0.048 & 0.016 & 0.091 \\
\hline
\end{tabular}

Source: DOLS results in Table 3 and the underlying data. In the column labeled 'Domestic' the domestic R\&D stock is allowed to grow over time while the foreign R\&D stocks are held constant at their initial levels. The value shown in the Domestic column then is the cross-sectional growth in productivity that would have occurred if the foreign $R \& D$ stocks had not changed from their initial levels. The same technique is repeated in the next two columns for each of the foreign R\&D stocks.

${ }^{7}$ Since the dynamic OLS technique requires leads and lags of the differenced regressors, the sample is reduced to the years 1974 to 1989 . 
productivity, based on the DOLS results in Table 2. The first two columns report the actual and predicted growth in TFP from 1974 to $1989 .{ }^{7}$ The last three columns decompose the predicted growth in TFP into the parts attributable to domestic research, the research in similar countries, and the research in dissimilar nations. In the 'Domestic' column the domestic R\&D stock grows over time while the foreign $R \& D$ stocks are held constant at their initial levels. The value shown in the Domestic column then is the productivity growth that would have occurred if the foreign $\mathrm{R} \& \mathrm{D}$ stocks had not changed from their initial levels. The same technique is repeated in the next two columns for each of the foreign R\&D stocks.

Domestic research accounts for about half of the predicted change in productivity for Tier 1 and about a quarter of the predicted changes in Tier 2 and Tier 3. The average masks substantial variation, as several nations would have experienced little growth without foreign knowledge flows. These estimates suggest the frontier nations are more reliant on their own innovative activities for growth than are less-advanced nations.

The decomposition reveals the effects of relative productivity on knowledge flows. For Tier 1 nations, the research of similar nations is far more potent than the research of less-advanced nations. The exception is Spain, which benefits almost equally from the research of similar and dissimilar nations. For Tier 2, the influence of knowledge flows from more-advanced nations appears on average far more influential than knowledge flows from similar nations. The exceptions are Germany and Switzerland, who receive few benefits from either foreign research stock. For Tier 3, research from more-advanced nations is again more potent than the research from similar nations. Every Tier 2 and Tier 3 nation except Germany and Switzerland received larger benefits from more-advanced nations than from similar nations.

The results portray the knowledge flow patterns implied by a simple model of catch-up to the frontier, with knowledge moving from advanced to lessadvanced nations. Each tier benefits more from frontier research than from the research conducted by similar or less-advanced nations. The actual effect of a technology gap between the source and destination countries seems small: there is little difference between the benefits enjoyed by the average Tier 1 nation from frontier research and the benefits enjoyed by the average Tier 2 or Tier 3 nation. These results imply that only a few countries generate beneficial knowledge flows. This finding is consistent with Nadiri and Kim's (1996) and Branstetter's (1996) findings that only a few countries generate sizable 
knowledge flows. The results in this study points to relative productivity as an explanation for the previous results. The findings here are consistent with the premise that the research of less-developed countries is mainly orientated towards interpreting the results and the new products emerging from the research of more-advanced countries. ${ }^{8}$

\section{A. Robustness Tests}

The criterion used to classify the countries was somewhat arbitrary. To check the criterion's robustness, the countries were grouped based on the 1971 relative GDP per worker, with data from the Penn World Tables. If the domestic to foreign relative productivity levels is between .5 and 1.35 , the foreign country is defined

Table 4. Knowledge Diffusion-Real GDP per Worker 1

\begin{tabular}{|c|c|c|c|}
\hline & OLS & FMOLS & DOLS \\
\hline $\mathrm{S}^{\mathrm{d}}$ & $.063(8.16)^{*}$ & $.060(4.15)^{*}$ & $.068(3.94)^{*}$ \\
\hline $\mathrm{G} 7 * \mathrm{~S}^{\mathrm{d}}$ & $.096(6.96)^{*}$ & $.089(2.99)^{*}$ & $.069(1.95)^{* *}$ \\
\hline SIMILAR & $.081(3.02)^{*}$ & $.117(3.04)^{*}$ & $.123(2.69)^{*}$ \\
\hline TIER $2 *$ SIMILAR & $.109(2.83)^{*}$ & $.076(1.24)$ & $.094(1.28)$ \\
\hline TIER3*SIMILAR & $-.004(-0.13)$ & $-.096(-2.08)^{*}$ & $-.177(-3.24) *$ \\
\hline OTHER & $-.033(-2.46)^{*}$ & $-.049(-2.68) *$ & $-.055(-2.50)^{*}$ \\
\hline TIER $2 *$ OTHER & $.040(1.59)$ & $.026(0.71)$ & $.020(0.46)$ \\
\hline TIER3*OTHER & $.062(2.29)^{*}$ & $.085(2.09)^{*}$ & $.167(3.44) *$ \\
\hline $\begin{array}{l}\text { LM test } \\
\mathrm{H}_{\mathrm{o}} \text { : cointegration }\end{array}$ & - & $\begin{array}{l}-5.28 \\
\text { Fail to Reject }\end{array}$ & $\begin{array}{l}-4.80 \\
\text { Fail to Reject }\end{array}$ \\
\hline
\end{tabular}

Notes: Dependent variable=TFP (total factor productivity Coe and Helpman (1995) indices), Number of observations $=352$, LM test values less than 1.645 indicate cointegration. $S^{d}=$ domestic R\&D stock; SIMILAR=foreign $\mathrm{R} \& \mathrm{D}$ stock from similar nations. All variables are indexed and are in log-levels. OTHER=foreign R\&D stock from dissimilar nations; G7=dummy for the G7. Tier 1=USA, Canada, Australia, Netherlands, New Zealand, Sweden, Switzerland. Tier 2= Germany (West), France, Italy, United Kingdom, Austria, Belgium, Denmark, Finland, Norway. Tier 3=Japan, Greece, Ireland, Israel, Portugal, Spain, Absolute $T$-statistics in parentheses. $*$ = significant at the 5\% level. 1 lead and 2 lags of the first-differences of the nonstationary regressors were included in the DOLS regression. All equations include unreported group fixed effects. The estimation was performed in GAUSS using the programs for FMOLS and DOLS provided by Kao on his internet homepage http://web.syr.edu/ cdkao/

${ }^{8}$ Given that this sample includes only the relatively advanced OECD nations, it is possible that the effect of a technology gap on knowledge flows would be more apparent in a sample that included developing countries. 
as SIMILAR. For relative productivity levels less than .5 or greater than 1.35 , the foreign country is classified as OTHER. The choice of the cutoff points of .5 and 1.35 is partially motivated by the desire to generate tiers with reasonably balanced numbers of countries. For Tier 1 nations, there are no other nations in the sample with a real GDP per worker greater than 1.35 of their own. The Tier 3 counties have no foreign country with a relative output per worker less than half of their own. Tier 1 now has 7 countries (USA, Canada, Australia, Netherlands, New Zealand, Sweden, Switzerland), Tier 2 has 9 countries (France, Germany, Italy, United Kingdom, Austria, Belgium, Denmark, Finland, Norway), and Tier 3 has 6 countries (Japan, Greece, Ireland, Israel, Portugal, Spain).

Table 4 provides the results from this different relative productivity measure and classification scheme. The results are substantially similar to the earlier findings. However, with relative productivity defined at the beginning of the sample, it is more difficult to distinguish between the Tier 1 and Tier 2 countries. The Tier 2 coefficients are generally insignificant. Nonetheless, the same pattern of knowledge flows remains obvious. Nations benefit more from the R\&D of relatively more-advanced nations than from the $R \& D$ of similar nations. Relative productivity levels are less important than the distance to the frontier.

Keller (1998) criticizes the use of trade-based weights in the construction of foreign R\&D stocks. Using OLS, he finds that foreign R\&D stocks created using random weights yield results similar to results from trade-weighted foreign $R \& D$ stocks. His interpretation is that the choice of weights is uninformative of the knowledge transmission channel. While this study does not focus on the role of trade in transmitting knowledge, the choice of weights may affect the findings.

Keller's test is therefore performed to examine the role of the weights. As before, two foreign R\&D stocks are formed for similar and dissimilar countries. However, instead of using trade-based weights, the foreign R\&D stocks are constructed using randomly generated weights. Once the randomly-weighted foreign R\&D stocks are generated, estimation is performed using OLS, FMOLS and DOLS. The entire procedure from the construction of randomly-weighted foreign R\&D stocks to the estimation was then repeated 1000 times.

Table 5 reports the average coefficient and average t-statistic from this Monte Carlo-style robustness test. For Tier 1, the research of less-advanced nations now appears more influential. Tiers 2 and 3 both benefit more from the research of similar countries and less from the research of advanced countries than they did using trade weights. Unlike in Keller, the use of trade weights appears 
Table 5. Knowledge Diffusion-Random Weights

\begin{tabular}{|l|c|c|c|}
\hline & OLS & FMOLS & DOLS \\
\hline $\mathrm{S}^{\mathrm{d}}$ & $.020(1.85)^{* *}$ & $.0 .13(0.54)$ & $.020(1.85)^{* *}$ \\
$\mathrm{G} 7 \mathrm{~S}^{\mathrm{d}}$ & $.092(4.92)^{*}$ & $.083(1.96)^{*}$ & $.092(4.92)^{*}$ \\
$\mathrm{SIMILAR}$ & $.173(5.53)^{*}$ & $.186(3.07)^{*}$ & $.173(5.53)^{*}$ \\
TIER2*SIMILAR & $-.008(-0.34)$ & $-.011(-0.24)$ & $-0.01(-0.38)$ \\
TIER3*SIMILAR & $-.076(-3.17)^{* *}$ & $-.085(-1.84)^{* *}$ & $-.076(-3.17)^{*}$ \\
& & & \\
OTHER & $.057(1.83)^{* *}$ & $.049(0.89)$ & $.057(1.83)^{* *}$ \\
TIER2*LEADERS & $.034(1.37)$ & $.040(0.94)$ & $.034(1.37)$ \\
TIER3*OTHER & $.025(0.95)$ & $.034(0.77)$ & $.024(0.95)$ \\
\hline
\end{tabular}

Notes: Dependent variable=TFP (total factor productivity Coe and Helpman (1995) indices), Number of observations $=352$, Reported coefficients and $T$-statistics are the averages from 1000 repetitions. Experiment was performed in GAUSS, with the initial random number generator seed value set at 26875. All variables are indexed and are in log-levels. Similar=foreign R\&D stock from similar nations; Other $=$ foreign $R \& D$ stock from dissimilar nations; $G 7=$ dummy for the G7. Average absolute $T$-statistics in parentheses. *=significant at the $5 \%$ level. 1 lead and 2 lags of the first-differences of the nonstationary regressors were included in the DOLS regression. All equations include unreported group fixed effects. $S^{d}=$ domestic R\&D stock

informative: knowledge flows from the frontier are much larger when trade patterns reflect access to knowledge. This finding helps explain the Ben-David (1997) result that countries trading heavily with relatively advanced nations enjoy faster growth.

\section{Interpretation and Conclusion}

Are knowledge flows limited by relative productivity levels or affected by the distance to the technological frontier? This paper uses OECD data on research and productivity and recently developed panel cointegration methods to provide an answer. Knowledge flows within tiers are dominated by flows from frontier nations. Moreover, knowledge flows from the frontier increase with the recipients distance from the frontier. Frontier nations receive research spillovers primarily from other frontier nations. Less-advanced nations receive research spillovers from similar and more-advanced nations, but the research from advanced nations has a larger estimated impact on productivity. For the average low productivity country, research of more-advanced nations contributes about twice as much to productivity growth as research from similar nations. These estimates suggest that 
the influence of relative productivity on knowledge flows is consistent with a simple model of catch-up to a technological frontier. The results do not support models of convergence that suggest knowledge flows between technologically similar nations may prove more beneficial.

The literature on international knowledge flows has previously focused on linking knowledge flows to trade flows. The results here indicate that given equal trade flows from two foreign nations, domestic productivity will be most enhanced by the knowledge flowing from the more-advanced of the two. The findings support BenDavid's (1997) argument that countries trading heavily with relatively advanced nations enjoy faster growth. Additionally, much of the international knowledge flow literature implicitly assumes all OECD countries generate knowledge flows. The evidence seems to undermine that assumption. Knowledge flows are found emerging only from the most advanced OECD nations. Future work should address whether the knowledge flow pattern uncovered here is also appears at disaggregated levels and whether it extends to developing countries.

Date accepted: 31 August 2000

\section{References}

Abramovitz, Moses (1986), "Catching Up, Forging Ahead, and Falling Behind" Journal of Economic History 46, 385-406.

Aghion, Philippe and Peter Howitt (1998), Endogenous Growth Theory, Cambridge, MIT Press.

Ben-David, Dan (1997), “Catch-up, Trade, and Technological Diffusion,” manuscript.

Bernard, Andrew B. and Charles I. Jones (1996a), "Productivity Across Industries and Countries: Tmes Series Theory and Evidence," The Review of Economics and Statistics 75, 135-146.

(1996b), "Comparing Apples to Oranges: Productivity Convergence and Measurement Across Industries and Countries," American Economic Review 86, 1216-1238.

Branstetter, L. (1996), “Are Knowledge Spillovers International or Intranational in Scope? Microeconometric Evidence from the US and Japan,” NBER Working Paper No. 5800.

Coe, David T. and Elhanan Helpman (1995), "International R\&D Spillovers," European Economic Review 39, 859-887.

Eaton, Jonathan and Samuel Kortum (1996), "Trade in Ideas: Patenting and Productivity in the OECD," Journal of International Economics 40, 251-278.

Engelbrecht, Hans-Jurgen (1998), "International R\&D Spillovers, Human Capital and 
Productivity in OECD Economies: An Empirical Investigation," European Economic Review 42(8), 1479-88.

Evenson, Robert E. (1997), "Industrial Productivity Growth Linkages between OECD Countries, 1970-90” Economic Systems Research 9(2), 221-30.

Griliches, Zvi (1979), "Issues in Assessing the Contribution of Research and Development to Productivity Growth,” Bell Journal of Economics 10, 92-116.

(1991), "The Search for R\&D Spillovers," NBER Working Paper No. 3768.

Grossman, Gene M. and Elhanan Helpman (1991), Innovation and Growth in the Global Economy. Cambridge, MIT Press.

Hall, Robert and Charles Jones (1999), "Why Do Some Countries Produce so Much More Output Per Worker than Others ?" Quarterly Journal of Economics 114(1), 83-116.

Im, Kyung So, Pesaran, M Hashem, and Yongcheol Shin (1995), "Testing for Unit Roots in Heterogeneous Panels." University of Cambridge Department of Applied Economics Working Paper, Amalgamated Series 9526.

Inder, Brett (1993), "Estimating Long-run Relationships in Economics: A Comparison of Different Approaches," Journal of Econometrics 57, 53-68

Jaffe, Adam (1986), “Technological Opportunity and Spillovers of R\&D: Evidence from

Firms' Patents, Profits, and Market Value," American Economic Review 76, 984-1000.

Kao, Chihwa and Min-Hsien Chiang (1999), "On the Estimation and Inference of a Cointegrated Regression in Panel Data," manuscript, Syracuse University. and Chen, B. (1999), "International R\&D Spillovers: An Application of

Estimation and Inference in Panel Cointegration," Oxford Bulletin of Economics and Statistics 61(S1), 691-709.

Keller, Wolfgang (1997), “Trade and the Transmission of Technology,” mimeo.

(1998), “Are International R\&D Spillovers Trade-related? Analyzing Spillovers Among Randomly Matched Trade Partners," European Economic Review 42(8), 1469-81.

Levin, Andrew and Chien-Fu Lin (1993), "Unit Root Tests in Panel Data: New Results," UC-San Diego Working Paper No. 93-56, 1-35.

McCoskey, S., and Kao, C. (1998), “A Residual-Based Test of the Null of Cointegration in Panel Data," Econometric Reviews 17(1), 57-84.

Nadiri, M. Ishaq., and Kim, S. (1996), "International R\&D Spillovers, Trade, and Productivity in Major OECD Countries,” NBER Working Paper, No. 5801.

Pedroni. P. (1996), "Fully Modified OLS for Heterogeneous Cointegrated Panels and the Case of Purchasing Power Parity," Indiana University Working Papers in Economics, 96-20.

Phillips, P., and Hansen, B. (1990), "Statistical Inference in Instrumental Variables Regression with I(1) Processes," Review of Economic Studies 53, 473-495.

Saikkonen, Pentti (1991), "Estimation of Cointegration Regressions," Econometric Theory 58, 1-21. 